\title{
Radiation-Induced Stable Radicals in Calcium Phosphates: Results of Multifrequency EPR, EDNMR, ESEEM, and ENDOR Studies
}

\author{
Fadis F. Murzakhanov ${ }^{1, *(D)}$, Peter O. Grishin ${ }^{2}$, Margarita A. Goldberg ${ }^{3} \mathbb{D}$, Boris V. Yavkin ${ }^{1} \mathbb{D}$, Georgy V. Mamin $^{1}$, \\ Sergei B. Orlinskii ${ }^{1}$, Alexander Yu. Fedotov ${ }^{3}$, Natalia V. Petrakova ${ }^{3}$, Andris Antuzevics ${ }^{4}$, Marat R. Gafurov ${ }^{1}$ (D) \\ and Vladimir S. Komlev ${ }^{3}$ (D) \\ 1 Institute of Physics, Kazan Federal University, 18 Kremlevskaya Str., 420008 Kazan, Russia; \\ boris.yavkin@gmail.com (B.V.Y.); George.Mamin@kpfu.ru (G.V.M.); orlinskii@list.ru (S.B.O.); \\ marat.gafurov@kpfu.ru (M.R.G.) \\ 2 Dentistry Faculty, Kazan State Medical University, 49 Butlerova Str., 420000 Kazan, Russia; phlus8@mail.ru \\ 3 A.A. Baikov Institute of Metallurgy and Materials Science, Russian Academy of Sciences, 49 Leninsky pr., \\ 119334 Moscow, Russia; margo.goldberg@yandex.ru (M.A.G.); antishurik@mail.ru (A.Y.F.); \\ petrakova.nv@mail.ru (N.V.P.); komlev@mail.ru (V.S.K.) \\ 4 Institute of Solid State Physics, University of Latvia, Kengaraga str. 8, 1000 Riga, Latvia; \\ andris.antuzevics@cfi.lu.lv \\ * Correspondence: murzakhanov.fadis@gmail.com; Tel.: +7-9270395512
}

Citation: Murzakhanov, F.F.; Grishin, P.O.; Goldberg, M.A.; Yavkin, B.V.; Mamin, G.V.; Orlinskii, S.B.; Fedotov, A.Y.; Petrakova, N.V.; Antuzevics, A.; Gafurov, M.R.; et al.

Radiation-Induced Stable Radicals in Calcium Phosphates: Results of Multifrequency EPR, EDNMR, ESEEM, and ENDOR Studies. Appl. Sci. 2021, 11, 7727. https://doi.org/ 10.3390/app11167727

Academic Editor: Vittorio Checchi

Received: 10 July 2021

Accepted: 20 August 2021

Published: 22 August 2021

Publisher's Note: MDPI stays neutral with regard to jurisdictional claims in published maps and institutional affiliations.

Copyright: (c) 2021 by the authors. Licensee MDPI, Basel, Switzerland. This article is an open access article distributed under the terms and conditions of the Creative Commons Attribution (CC BY) license (https:/ / creativecommons.org/licenses/by/ $4.0 /)$.

\begin{abstract}
This article presents the results of a study of radiation-induced defects in various synthetic calcium phosphate $(\mathrm{CP})$ powder materials (hydroxyapatite- $-\mathrm{HA}$ and octacalcium phosphate-OCP) by electron paramagnetic resonance (EPR) spectroscopy at the $\mathrm{X}, \mathrm{Q}$, and $\mathrm{W}$-bands $(9,34,95 \mathrm{GHz}$ for the microwave frequencies, respectively). Currently, CP materials are widely used in orthopedics and dentistry owing to their high biocompatibility and physico-chemical similarity with human hard tissue. It is shown that in addition to the classical EPR techniques, other experimental approaches such as ELDOR-detected NMR (EDNMR), electron spin echo envelope modulation (ESEEM), and electronnuclear double resonance (ENDOR) can be used to analyze the electron-nuclear interactions of CP powders. We demonstrated that the value and angular dependence of the quadrupole interaction for ${ }^{14} \mathrm{~N}$ nuclei of a nitrate radical can be determined by the EDNMR method at room temperature. The ESEEM technique has allowed for a rapid analysis of the nuclear environment and estimation of the structural positions of radiation-induced centers in various crystal matrices. ENDOR spectra can provide information about the distribution of the nitrate radicals in the OCP structure.
\end{abstract}

Keywords: calcium phosphate; radiation-induced center; hyperfine interaction; EDNMR; ESEEM; ENDOR

\section{Introduction}

Nowadays, bone diseases, which are mainly caused by infections, defects, tumors, and injuries, are among the most common pathologies in clinical practices. It is certain that these defects require an appropriate bone treatment, without which irreversible consequences up to invalidity can occur. One of the most difficult but effective methods of treatment is surgery, with the subsequent replacement of the damaged area. One of the main aspects of bone treatment is the type and quality of materials used as a base for implants, which will determine the future successful healing of patients. Therefore, the creation and investigation of novel synthesized materials is gaining increasing interest in physics, biology, chemistry, and medicine [1-4].

Currently, there are a number of suitable materials for bone substitution such as inert metals (titanium- and tantalum-based alloys), polymers (polycaprolactone, cellulose, collagen), and ceramics (bioglass, gypsum, calcium carbonate) $[2,5,6]$. However, it is considered that calcium phosphate $(\mathrm{CP})$-based compounds are the most favorable choice 
for the reliable restoration of human hard-tissue defects due to their chemical stability and compositional similarities to the inorganic, mineral phase of the bone. At the same time, processes of biomineralization have attracted scientific and technological attention for a long time in view of creating personalized, non-toxic materials for bone and dental tissue engineering [7-9], myocardial tissue regeneration [10], bioimaging and drug delivery [11,12], tumor hypothermal treatment [13], tracking of the course of pathological calcification [14], etc. Several inorganic phases are involved in biomineralization, generally presented as non-stoichiometric carbonate-substituted calcium phosphates, among which the following are of the most importance: hydroxyapatite (HA, chemical formula $\left.\mathrm{Ca}_{10}\left(\mathrm{PO}_{4}\right)_{6}(\mathrm{OH})_{2}\right)$, tricalcium phosphate (TCP, chemical formula $\left.\mathrm{Ca}_{3} \mathrm{PO}_{4}\right)$, dicalcium phosphate dihydrate (DCPD, $\mathrm{CaHPO}_{4} \times 2 \mathrm{H}_{2} \mathrm{O}$, brushite), and octacalcium phosphate $(\mathrm{OCP}$, $\left.\mathrm{Ca}_{8} \mathrm{H}_{2}\left(\mathrm{PO}_{4}\right)_{6} \times 5 \mathrm{H}_{2} \mathrm{O}\right)$.

At present, $\mathrm{CP}$-based materials are commonly used in medicine and dentistry since they have shown excellent biocompatibility, osteoconductivity, and suitable mechanical properties. All of these $\mathrm{CP}$ materials provide the conditions for inducing osteoblast differentiation and improving the viability and proliferation of the bone cells $[15,16]$. Such suitable properties have contributed to the use of these materials in a wide range of other biological applications, e.g., drug and gene delivery, as a filler for biocomposites, transfection processes, as fluorescing probes and biomarkers in nanomedical applications $[17,18]$.

At the same time, there are a lot of emerging applications in addition to the biomedical ones. For example, OCP has demonstrated a good capacity for the defluorization of water [19], which has previously been demonstrated for HA [20]. HA has also been applied as a catalyst and catalyst support [21]. HA and cation-doped HA in the form of nanoparticles were used for the environmentally friendly oxidative desulfurization of oil [22] and light gas oil [23]. Likewise, HA was presented as an efficient and reusable catalyst for the epoxidation of olefins and $\alpha, \beta$-unsaturated ketones using hydrogen peroxide under relatively mild conditions [24]. Recently, the nitrate doping of CP nanoparticles was proposed for potential use as $(\mathrm{P}, \mathrm{N})$ nanofertilizers in agricultural applications [25], and EPR was recognized as one of the fastest methods of evaluating the presence and amount of nitrates. It is also known that HA is applied as an adsorbent for water purification [26], including the removal of nitrate due to its adsorption onto CP surfaces [27].

An extremely deep understanding of the physical, chemical, or biological processes that occur in crystal structures is required to develop or promote any field of materials science. This is especially important for new or poorly studied materials that have recently been obtained with a new chemical composition. However, it often happens that for a certain type of material, one distinct method is not sufficient to get the whole set of structural information. For disordered materials such as CPs, all available experimental tools are required to determine the more interesting features of doped materials. The magnetic resonance approach is a suitable experimental means that significantly complements and expands the knowledge of doped materials. Magnetic resonance-based methods can provide an insight into interatomic interactions, define their origin/mechanisms, and study the local environment of impurity centers, which cannot be directly analyzed by other techniques.

Calcium phosphate materials have been thoroughly studied by various experimental techniques. Most of the published CP-related articles can be categorized into studies of the morphology of nanoparticles, the structure of the crystal lattice, and the biological properties of the synthesized materials [1,2]. To solve problems with the structural analysis of $\mathrm{CP}$ powders, combinational approaches are utilized by applying Fourier transform infrared spectroscopy, scanning electron microscopy, X-ray diffraction, differential thermal and thermogravimetric analysis, Raman spectroscopy, as well as in vivo/in vitro analysis for the study of biological properties [28]. The abovementioned methods allow for the determination of the size and shape of nanoparticles, the presence of different functional groups, and additional crystalline phases as well as the lattice structure, depending on the type/concentration of impurity ions [3,5]. However, questions concerning the magnetic 
behavior/origin of defects and their electron-nuclear interactions with the local ionic environment remain unexplored, requiring additional experimental methods.

One of the analytical, non-destructive tools for the investigation of $\mathrm{CPs}$ of both biogenic and synthetic origins is electron paramagnetic resonance (EPR) [29-43]. The increased sensitivity, spectral and temporal resolution, along with the improved stability of modern commercial EPR spectrometers has opened new possibilities in the study of CPs during the last decade, taking a step towards in situ EPR imaging (EPRI) [44]. Pure, non-substituted $\mathrm{CPs}$ are EPR-silent. Consequently, conventional EPR can be used for the purity check of $\mathrm{CP}$ materials, for example, the presence of metal impurities [31]. A standard way of studying EPR-silent CPs is through the creation of certain types of defects with ionizing radiation such as $X-, \beta-, \gamma$-rays or ultraviolet light, and the investigation of their spectroscopic properties. Several radiation-induced paramagnetic species (anion radicals) located at hydroxyl or phosphate sites have been identified in synthetic HA, depending mainly on the nature of the biogenic materials and synthesis route/treatment of the artificial compounds as well as on the radiation conditions [45-49]. Among them, oxygen radicals $\mathrm{O}^{-}$, trapped atomic hydrogen centers, holes trapped on $\mathrm{OH}^{-}$and $\mathrm{PO}_{4}^{2-}$, carbonate radicals $\mathrm{CO}_{2}^{-}, \mathrm{CO}_{3}^{-}$, $\mathrm{CO}_{3}^{3-}$, and color centers have been observed. In burnt bones, coal-type C-radicals have been identified $[41,50]$. Besides material characterization, the spectroscopic and relaxation parameters of the observed paramagnetic centers can be used to track the radiation dose in HA-containing dental enamel [41], to follow the processes of calcification [29] and the doping/co-doping of synthetic materials with various ions [35,38]. The effect of diverse amino acids on the local microstructure of calcium-deficient hydroxyapatite was also tracked/confirmed by EPR spectroscopy [51].

As mentioned above, the EPR method is a well-established approach for the study of disordered materials such as CPs. However, we should accept the fact that this method has several limitations (low spectral resolution and technical restrictions) that do not allow us to resolve weak hyperfine interactions. The main problems arise from line broadening and signal overlapping. Therefore, important information about the local nuclear environment remains unexplored. More complicated approaches in hardware and better physical understanding have led to the advancement of magnetic resonance techniques. However, methods based on double resonance techniques for the study of disordered materials are still not used as widely as would be expected. In this article, we will demonstrate that there are a number of interesting techniques, which are targeted to the study of weak hyperfine splittings, allowing us to study local atomic (nuclear) surroundings. Such methods as electron spin echo envelope modulation (ESEEM), electron nuclear double resonance (ENDOR), and electron-electron double resonance (ELDOR) detected NMR (EDNMR) provide information that is related to the NMR spectroscopy approach and obviously cannot be obtained by conventional EPR. The corresponding experimental data (Larmor frequencies of nuclei, the values of hyperfine and quadrupole interactions with angularselected measurements) significantly complement and deepen the existing understanding of the structural behavior of $\mathrm{CP}$ materials.

The diverse field of pulse EPR spectroscopy allows us to obtain a complete set of spectroscopic and dynamic parameters for the radiation-induced centers in calcium phosphate materials. The parameters of the spin Hamiltonian (anisotropic $g$-factor, hyperfine $A$ and quadrupole $P$ interaction matrices) reflect the local symmetry of the defect position. The extent of anisotropy and principal values of the tensors depend on the electron density, the distribution of nearby ions, and the local gradients of electric fields. Additional quantum chemical methods can be employed to calculate the listed energy characteristics, which are determined by the structural features of defects as well as the localization of impurity ions in the vicinity. Thus, a comparative analysis of experimental data from pulse EPR spectroscopy with further theoretical calculations is crucial for a more complete understanding of the structural features of the crystal lattice of calcium phosphate materials. The explicit identification of certain paramagnetic centers is important for biphasic materials $(\mathrm{HA}+\mathrm{TCP})$, which are now generating great interest in dentistry [52]. For the successful 
characterization of biphasic compounds, a comprehensive understanding of structural nuances in single-phase materials is required.

The experimentally obtained data in this article (anisotropic $g$-factors, hyperfine $A$ and quadrupole $P$ interaction values) for different impurity centers can be used as a reference point for further theoretical calculations based on quantum chemistry (e.g., the density functional theory-DFT approach), which would allow for the acquisition of additional structural information about the features of the doped crystal lattice.

\section{Materials and Methods}

\subsection{Sample Synthesis}

HA powders were synthesized by precipitation from aqueous solutions according to the reaction (Equation (1)), using reactants of analytical grade (Labtech, Russia) and deionized water:

$$
10 \mathrm{Ca}\left(\mathrm{NO}_{3}\right)_{2}+6\left(\mathrm{NH}_{4}\right)_{2} \mathrm{HPO}_{4}+8 \mathrm{NH}_{4} \mathrm{OH} \rightarrow \mathrm{Ca}_{10}\left(\mathrm{PO}_{4}\right)_{6}(\mathrm{OH})_{2}+20 \mathrm{NH}_{4} \mathrm{NO}_{3}+6 \mathrm{H}_{2} \mathrm{O}
$$

The ammonium phosphate solution was added dropwise into a calcium nitrate solution during the stirring. The $\mathrm{pH}$ of the reaction mixture was maintained at a value of $11.0-12.0$ by adding aqueous ammonia. After the synthesis, the mixture was ripened for 21 days for the crystallization of the precipitate [53].

The powder of OCP was synthesized by hydrolysis of the initial DCPD powder in a buffer solution. A total of $10 \mathrm{~g}$ of DCPD powder was immersed in $1000 \mathrm{~mL}$ of $1.5 \mathrm{M}$ sodium acetate aqueous solution, with a $\mathrm{pH}$ value of $8.8 \pm 0.2$. The powder was kept in the solution for $24 \mathrm{~h}$, with a constant stirring rate at $35^{\circ} \mathrm{C}$, and then thoroughly washed in distilled water and dried overnight at $37^{\circ} \mathrm{C}$.

The jawbone material of a Vietnamese mini-pig (a mineral phase that consists mainly of hydroxyapatite) was extracted by removing an implant with small bone fragments of peri-implant tissues. The corresponding preparation of the jawbone sample for EPR measurements was carried out by separating it from the implant and sawing it into blocks. All requirements and relevant ethical standards for interventionary studies involving animals were rigorously followed according to the Local Ethics Committee of the Federal State Budgetary Educational Institution "Kazan State Medical University" of the Ministry of Health of the Russian Federation.

The studied samples were in dry powder form, which facilitated sample preparation before experiments. Standard quartz flasks were used for all types of EPR spectroscopy measurements at different frequency ranges. Since the Bruker Elexsys spectrometers use a resonator system (the dimensions of which are proportional to the microwave length), the sizes of the flasks (cylindrical sample holders) for each range were different: $7 \mathrm{~mm}, 3 \mathrm{~mm}$, and $0.6 \mathrm{~mm}$ for the $\mathrm{X}, \mathrm{Q}$, and $\mathrm{W}$-bands, respectively. The volume/mass of each sample corresponded to a fully filled resonator, ensuring a fill factor of $K=1$. A quantitative assessment of the radiation-induced center concentration was not carried out; therefore, the specific mass of the samples was not relevant. For X-ray and $\gamma$ irradiation, the powder samples were packaged in plastic containers and plastic bags, and irradiated in air at room temperature.

\subsection{Experimental Setup}

Conventional (continuous wave- $-\mathrm{CW}$ ) and pulsed EPR measurements were performed, exploiting the abilities of Bruker Elexsys 580/680 spectrometer in X- $\left(v_{\mathrm{MW}}=9-10 \mathrm{GHz}\right)$, Q- $\left(v_{\mathrm{MW}}=33-34 \mathrm{GHz}\right)$, and $\mathrm{W}$-band $\left(v_{\mathrm{MW}}=94-95 \mathrm{GHz}\right)$ ranges. At $\mathrm{CW}$ mode, experimental parameters (amplitude modulation, power of mw-source, and integration times) were chosen to avoid any distortion and saturation of absorption signals. Electron spin echo (ESE)-detected EPR spectra were recorded using a standard Hahn echo sequence with $\pi=32 \mathrm{~ns}$ and $\tau=300 \mathrm{~ns}$ for the X-band, and $\pi=64 \mathrm{~ns}$ and $\tau=240 \mathrm{~ns}$ for the W-band, unless otherwise specified in the text. Relaxation time measurements were taken using a 2-pulse 
Hahn echo sequence and an inversion-recovery 3-pulse sequence for the spin-spin $T_{2}$ and spin-lattice $\mathrm{T}_{1}$ relaxation times, respectively.

Electron Spin Echo Envelope Modulation (ESEEM) was implemented using a wellknown two-pulse Hahn sequence: $\pi / 2-\tau-\pi$, where the length of $\pi$ was $32 \mathrm{~ns}$, and $\tau$ was equal to $200 \mathrm{~ns}$. In this method, the integral intensity of the electron spin echo (ESE) was recorded, depending on the time interval $\tau$ between two pulses at a fixed magnetic field. This parameter was increased to the required value (before the loss of information on nuclear modulations). To increase the sensitivity and spectroscopic resolution, the smallest possible step, $t=4 \mathrm{~ns}$, was chosen and the ESE was integrated only at its peak with an integration time of $t=4 \mathrm{~ns}$. Further spectral analysis of obtained results involved a Fourier transform using the program OriginPro.

Electron nuclear double resonance (ENDOR) experiments were conducted using special (for nuclei and electron) cavities and a scheme of simultaneous electron-nuclear excitations called the Mims pulse sequence: $\pi / 2-\tau-\pi / 2-\mathrm{T}-\pi / 2$, with an additional radiofrequency (RF) $\pi$-pulse inserted between the second and third microwave $\pi / 2$ pulses, where the length of $\pi / 2$ was $64 \mathrm{~ns}, \tau=250 \mathrm{~ns}, \mathrm{~T}=20 \mu \mathrm{s}$, and for the RF pulse, $\pi=18 \mu \mathrm{s}$. Since the Larmor frequency of the nuclei is less than for an electron by about 2000 times, and is consequently in the radio frequency range, an additional RF-source with a wide frequency range (1-200 MHz) was used to stimulate the NMR transitions. To increase the spectroscopic resolution and separate close nuclear frequencies or overlapping splitting from each other in the RF-scale, experiments were performed in the high-field part of the spectrometer $\left(\mathrm{W}\right.$-band, $\left.v_{\mathrm{MW}}=94 \mathrm{GHz}\right)$. Due to method requirements for $\mathrm{T}_{1}$ time measurements, the experiments were performed at a low temperature, $\mathrm{T}=50 \mathrm{~K}$.

The ELDOR-detected NMR (EDNMR) method for the electron-nuclear study is based on the electron-electron double resonance (ELDOR) approach. The additional ELDOR module E580-400U, and a dielectric ring resonator ER 4118X-MD5, were used to investigate double electron-electron transitions. In this case, the initial (main) source of microwave radiation acts as the observation frequency $\left(\mathrm{v}_{\mathrm{mw} 1}\right.$ or $\left.\mathrm{v}_{\mathrm{obs}}\right)$ at a fixed value $\left(v_{\mathrm{MW}}=9.59 \mathrm{GHz}\right)$. At the same time, module E580-400U is necessary for generating and varying the second independent microwave frequency $\left(\mathrm{v}_{\mathrm{mw} 2}\right.$ or $\left.\mathrm{v}_{\text {pump }}\right)$ in the range from 9.3 to $10 \mathrm{GHz}$. Owing to its adjustable Q-factor, the ER 4118X-MD5 resonator allows for the optimization of the bandwidth of resonant frequencies in accordance with the specific requirements of the experiment. The duration of the selective pulse $t_{\mathrm{sel}}$ was chosen to be $6 \mu \mathrm{s}$, which corresponds to the excitation band in the EPR spectrum, with $\Delta \mathrm{B}=7.2 \mu \mathrm{T}$ and the length of the detection pulse equal to $300 \mathrm{~ns}(\Delta \mathrm{B}=144 \mu \mathrm{T})$. All of these tuning parameters allow for the recording of the spectra at a high resolution.

To create stable paramagnetic centers in the nominal pure material, $\mathrm{X}$-ray irradiation of the synthesized powders was provided by a URS-55 source $(\mathrm{U}=55 \mathrm{kV}, \mathrm{I}=16 \mathrm{~mA}$, $\mathrm{W}$ anticathode) at room temperature for $30 \mathrm{~min}$, with the estimated dose of $10 \mathrm{kGy}$.

$\gamma$-ray irradiation was performed on a cyclic electron accelerator for 15 and $90 \mathrm{~min}$ (with the estimated doses of 4 and $25 \mathrm{kGy}$, respectively) at room temperature. Irradiation was carried out on a cyclic electron accelerator "Microtron-cT". The irradiation parameters were as follows: the electron energy was $21 \mathrm{MeV}$, the electron beam current was up to $5 \mu \mathrm{A}$, the pulse repetition rate was $200 \mathrm{~Hz}$, the pulse duration was $3 \mu \mathrm{s}$, the gamma-quantum flux was $5 \times 10^{13} \mathrm{~s}^{-1} \mathrm{~cm}^{-2}$. The duration of sample irradiation was 15 and $90 \mathrm{~min}$ at an electron beam current of $4 \mu \mathrm{A}$, with the estimated absorbed doses of about 4 and $25 \mathrm{kGy}$, respectively. The details of irradiation are provided in our paper [54].

\section{Results and Discussion}

\subsection{EPR Spectroscopy}

There are no paramagnetic centers in nominally pure samples (HA and OCP); therefore, no EPR signals in CP materials can be observed. An X-ray or $\gamma$-irradiation procedure performed on the samples leads to the formation of radiation centers that can be successfully detected by EPR (Figure 1). As we can see, the acquired EPR spectra from the 
irradiated samples have quite a strong anisotropy, with a characteristic splitting into hyperfine structures. Powder spectra of the radiation-induced centers (nitrate radicals) in CPs are very often described by a Spin-Hamiltonian of axial symmetry:

$$
H=g_{\|} \beta B_{z} S_{z}+g_{\perp} \beta\left(B_{x} S_{x}+B_{y} S_{y}\right)+A_{\|} S_{z} I_{z}+A_{\perp}\left(S_{x} I_{x}+S_{y} I_{y}\right)
$$

where $g_{||}$and $g_{\perp}$ are the main components of the $g$ tensor, $A_{||}$and $A_{\perp}$ are the main components of the hyperfine tensor, $B_{\mathrm{i}}, S_{\mathrm{i}}$, and $I_{\mathrm{i}}$ are the projections of the external magnetic field strength, electronic $(S=1 / 2)$, and nuclear $(I=1)$ spins, respectively, onto the $i=\{x, y, z\}$ coordinate axis, and $\beta$ is the Bohr magneton.
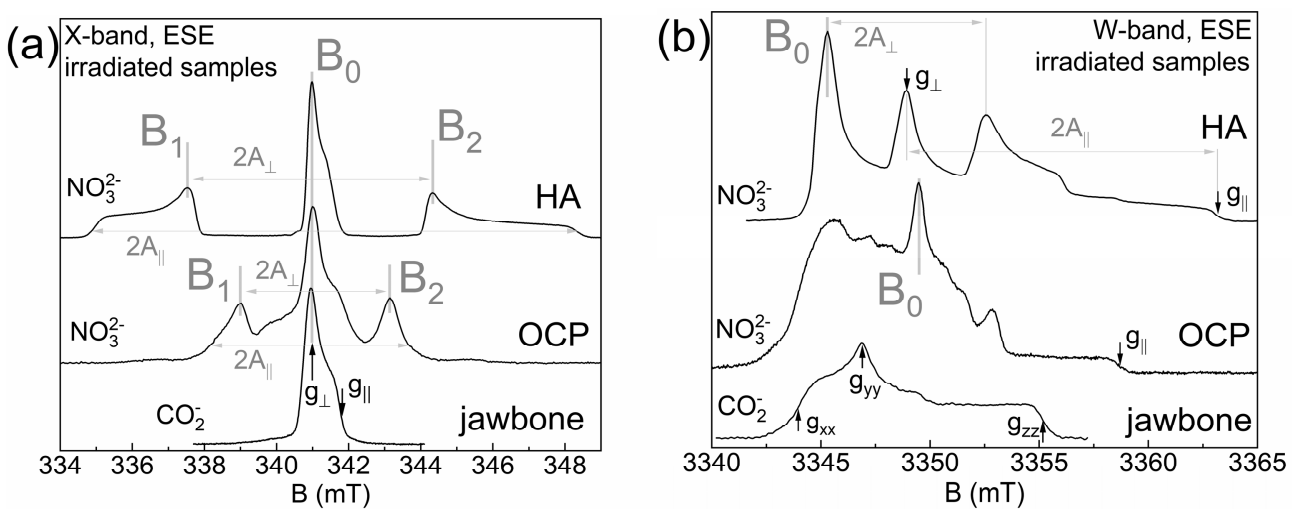

Figure 1. EPR spectra of the irradiated samples in pulse mode for the (a) X-band and (b) W-band frequency ranges at $\mathrm{T}=297 \mathrm{~K}$.

The Spin-Hamiltonian parameters for the same center may differ significantly, depending on the type of sample. The spectra of the $\mathrm{CP}$ samples synthesized from the nitrogen-containing reagents (see Equation (1)) can be described with the parameters that are shown in Table 1.

Table 1. The Spin-Hamiltonian parameters of the X-ray irradiated samples.

\begin{tabular}{cccccc}
\hline & $g_{\mathrm{xx}}$ & $g_{\mathrm{yy}}$ & $g_{\mathrm{zz}}$ & $A_{\perp}(\mathrm{mT})$ & $A_{||}(\mathrm{mT})$ \\
\hline jawbone & $2.0026(2)$ & $2.0008(2)$ & $1.996(1)$ & - & - \\
HA & $2.006(1)$ & $2.006(1)$ & $2.002(1)$ & $3.37(5)$ & $6.65(4)$ \\
OCP & $2.0014(3)$ & $2.0014(3)$ & $2.0035(5)$ & $2.08(5)$ & $2.50(5)$ \\
\hline
\end{tabular}

The shape of the EPR line and the splitting values for HA and OCP are very different. This may be due to the different atomic environments, the degree of distortion of the crystal lattice, or the level of delocalization of the paramagnetic center [55]. Differences in the parameters of the Spin-Hamiltonian should be useful for further analysis of crystal structures of samples doped with various cations.

It should be noted that the EPR spectra of CP samples differ in the degree of anisotropy in the experiment on the high-frequency part of the spectrometer (Figure 1b). Experimental measurements in two or more different frequency ranges allow for a description of the obtained results more accurately, i.e., unequivocally identify the paramagnetic centers and determine the parameters of the main interactions. The W-band EPR spectrum of OCP is more difficult to interpret, despite the fact that the values of the hyperfine interaction $\left(A_{11}\right.$ or $A_{\perp}$ ) are the smallest for the calcium phosphates group. It was concluded that in the irradiated HA samples, EPR is mainly due to the stable $\mathrm{NO}_{3}^{2-}$ ions, preferably substituting one distinct $\mathrm{PO}_{4}^{3-}$ position in the $\mathrm{HA}$ structure (substitution of the B-type), while there are several non-equivalent positions for the nitrate radical in the OCP structure. In our paper [55], we found that the distribution of $A_{\perp}$ for TCP is larger than that of the HA. We 
suggested that it could be due to the three different positions for $\mathrm{PO}_{4}$ group substitution in the TCP structure, as well as due to the various mechanisms for charge compensation.

Since hydroxyapatite is an inorganic mineral component of bone tissue, we studied the biogenic material after X-ray irradiation. As an example, the jawbone of a Vietnamese mini-pig was chosen for the EPR study. This sample, like synthetic hydroxyapatite, does not contain its own paramagnetic centers. However, after X-ray exposure, radiation-induced centers are formed. The EPR spectra of samples in two frequency ranges are shown in Figure 1. The signal is attributed to the stable carbonate radical, which is identified by the degree of rhombic anisotropy (shape of line) and the values of the $g$-factor (see Table 1). As we can see, all three values of the $g$-factor can be accurately determined due to the high spectroscopic resolution (at W-band), while for the X-band, it is possible to distinguish only perpendicular $\left(g_{\mathrm{xx}}=g_{\mathrm{yy}}=g_{\perp}\right)$ and parallel orientations $\left(g_{\mathrm{zz}}=g_{\mid ।}\right)$. At the same time, there is no evidence of a nitrate radical. Figure 1 clearly shows that the presence of free radicals in the irradiated sample depends on the type of biomaterial under study.

Relaxation characteristics were also investigated for the $\mathrm{CP}$ samples. The obtained data are shown in Table 2. As we can see, the relaxation times $\mathrm{T}_{1}$ (spin-lattice or longitudinal relaxation) and $T_{2}$ (spin-spin or transverse relaxation) differ depending on the type of $\mathrm{CP}$ material. This difference may indicate that the radiation-induced centers occupy various positions in the crystal lattices of $\mathrm{HA}, \mathrm{OCP}$, and biogenic compounds (jawbone of a Vietnamese mini-pig). Because of the difference in spin-spin relaxation times, we can conclude that there is an unequal distribution of free radicals for various $\mathrm{CP}$ materials. Therefore, a full set of spectroscopic values and dynamic characteristics of radiationinduced centers will allow us to unambiguously determine the nature of EPR signals in poorly studied CP materials (amorphous, biphasic, and doped materials).

Table 2. Relaxation characteristics of radiation-induced paramagnetic centers in different matrices at room temperature $\mathrm{T}=297 \mathrm{~K}$, in the $\mathrm{X}$-band frequency range $v_{\mathrm{MW}}=9.6 \mathrm{GHz}$. Values for $\mathrm{CP}$ materials were measured at $\mathrm{B}_{0}$ (see Figure 1a).

\begin{tabular}{ccc}
\hline Type of Material & $\begin{array}{r}\text { Spin-Lattice Relaxation } \\
\mathbf{T}_{\mathbf{1}}(\boldsymbol{\mu} \mathbf{s})\end{array}$ & $\begin{array}{c}\text { Spin-Spin Relaxation } \\
\mathbf{T}_{\mathbf{2}}(\boldsymbol{\mu} \mathbf{s})\end{array}$ \\
\hline HA & $28.5(5)$ & $3.0(1)$ \\
OCP & $60.7(8)$ & $0.68(5)$ \\
jawbone of a mini-pig & $17.7(2)$ & $1.31(8)$ \\
\hline
\end{tabular}

Samples irradiated by X-ray and $\gamma$-radiation were additionally explored in the Q-band microwave range. Experimental results are presented only in continuous wave mode at room temperature. Figure 2 shows the difference in the EPR spectra between the types of irradiation for the same type of material. The nature of the paramagnetic centers can be dependent on the type of radiation exposure. The influence of the type of radiation (and other radiation characteristics) on the EPR spectrum was extensively discussed in the literature $[56,57]$. However, for the OCP sample, the difference in the EPR spectra according to the type of irradiation is not observed. It may serve as additional proof to the conclusion made in ref. [54] that, in contrast to HA, the radiation-induced radicals in OCP are stabilized not in the apatite, but in the hydrated layers of OCP.

The results obtained in the Q-band frequency range provide additional information about the spectroscopic values of the spin system. But as we can see in the case of irradiated calcium phosphates, not all available frequency ranges are suitable for the analysis of powdered materials. The anisotropy of the $g$-factor for nitrate radicals in high magnetic fields is comparable to or even greater than the hyperfine interaction splitting, while at the $\mathrm{X}$-band, the converse can be observed. Therefore, measurements of the nitrogen radical in an intermediate frequency range lead to the formation of a complex EPR spectrum that is difficult to interpret. Nevertheless, in other cases, a comparison of the EPR spectra makes it possible to clearly determine the origin of the radiation-induced paramagnetic centers and calculate the parameters of the Spin-Hamiltonian. 

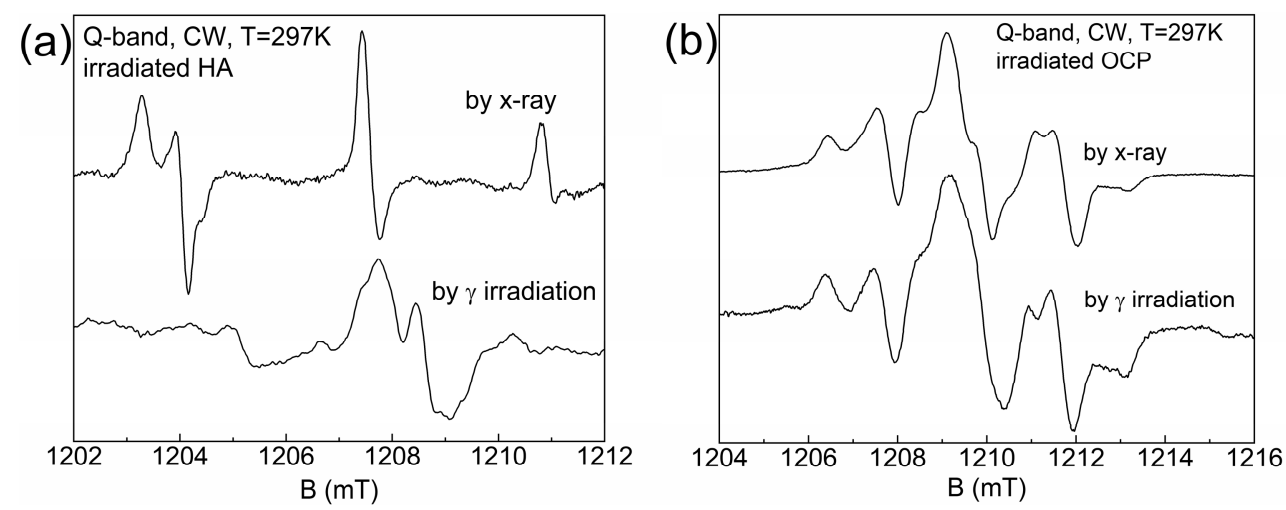

Figure 2. EPR spectra of the nitrate radical in (a) HA and (b) OCP in the Q-band frequency range at room temperature.

\subsection{EDNMR Spectroscopy Analysis}

The significant anisotropy of $g$ - and $A$-tensors and a relatively long transverse relaxation time $\left(\mathrm{T}_{2}=3 \mu \mathrm{s}\right.$ ) of the $\mathrm{NO}_{3}^{2-}$ radical (see Figure 1a) allows us to carry out angularselected EDNMR measurements at room temperature in the $\mathrm{X}$-band frequency range.

Signals corresponding to the Larmor frequencies of ${ }^{31} \mathrm{P}( \pm 6 \mathrm{MHz})$ and ${ }^{1} \mathrm{H}( \pm 14.8 \mathrm{MHz})$ nuclei are shown on the overview spectra at $\mathrm{B}_{0} \approx 0.34 \mathrm{~T}$ (Figure 3). These signals are expected because hydrogen and phosphorus ions are structural elements of the HA and indicate that the studied nitrogen radical is located in the HA crystal lattice. The lack of additional structures (or splitting) for these nuclei indicates an insufficient spectral resolution of the EDNMR method (at least at room temperature in the X-band). The most interesting signals are those observed at $v= \pm 47.5$ and $\pm 95 \mathrm{MHz}$. Given the theoretical calculations [58,59] for various electron-electron transitions as well as the known values of hyperfine structure $A$ from EPR measurements (Figure 1a), it follows that these transitions are caused by the anisotropic hyperfine interaction from nitrogen nuclei. Due to the fact that the value of $A$ exceeds the Larmor frequency of ${ }^{14} \mathrm{~N}$ nuclei $\left(\mathrm{I}=1, \mathrm{v}_{\text {Larmor }}=1.04 \mathrm{MHz}\right.$ for $\mathrm{B}_{0} \approx 0.34 \mathrm{~T}$ ), this leads to the localization of the EDNMR signal in the range of the half (for single-quantum transitions with $\Delta \mathrm{M}_{\mathrm{I}}= \pm 1$ ) and whole (for double-quantum transitions with $\Delta \mathrm{M}_{\mathrm{I}}= \pm 2$ ) values of $A$.
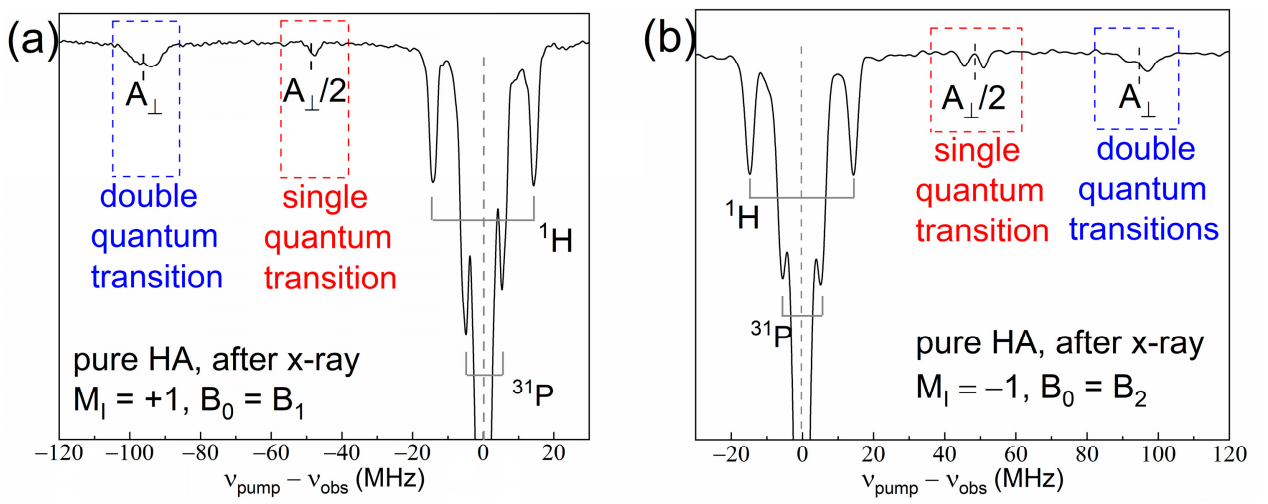

Figure 3. Total EDNMR spectra of $H A$ according to the quantum number $M_{I}:(a) M_{I}=+1$ at $B_{0}=B_{1}$, (b) $\mathrm{M}_{\mathrm{I}}=-1$ at $\mathrm{B}_{0}=\mathrm{B}_{2}$ (see Figure $1 \mathrm{a}$ ).

A more detailed analysis of the spectrum at $\Delta v>0\left(\mathrm{M}_{\mathrm{I}}=-1\right)$ shows an additional splitting for the single-quantum transition exactly localized at the value $A_{\perp} / 2$ (Figure 4). Using the expression for single-quantum transitions [58]:

$$
\Delta=2 v_{\text {Larmor }} \pm 3 P
$$


where $\Delta$ is the splitting value of single-quantum transitions, and a choice of the sign " \pm " depends on the quantum number of $M_{I}$ (" + " for $M_{I}=-1$ and " - " for $M_{I}=+1$ ), we concluded that the observed splitting occurs due to the presence of a quadrupole interaction of the ${ }^{14} \mathrm{~N}$ nuclei with a gradient of crystal field. Assuming that the tensors $A$ and $P$ are collinear, the value (and sign) of the quadrupole splitting can be calculated quite easily. Thus, we could establish that the value of quadrupole splitting $P=1.2 \mathrm{MHz}$. Due to the fact that the $P$ value is comparable to the Larmor frequency of ${ }^{14} \mathrm{~N}$ at $\mathrm{B}_{0}=340 \mathrm{mT}$, splitting in the same orientation for $\mathrm{M}_{\mathrm{I}}=+1$ is not observed. Additionally, EDNMR measurements were performed for an aluminum-doped hydroxyapatite within the frequency range of the single-quantum transitions. Although the substitution degree by aluminum ions was extremely high (up to $20 \%$ ), the value of quadrupole splitting was not changed. This means that the local environment of the nitrogen radical, i.e., the electric (crystal) field gradient, does not change significantly. Consequently, aluminum-doped hydroxyapatite up to $20 \%$ retains its initial space group.

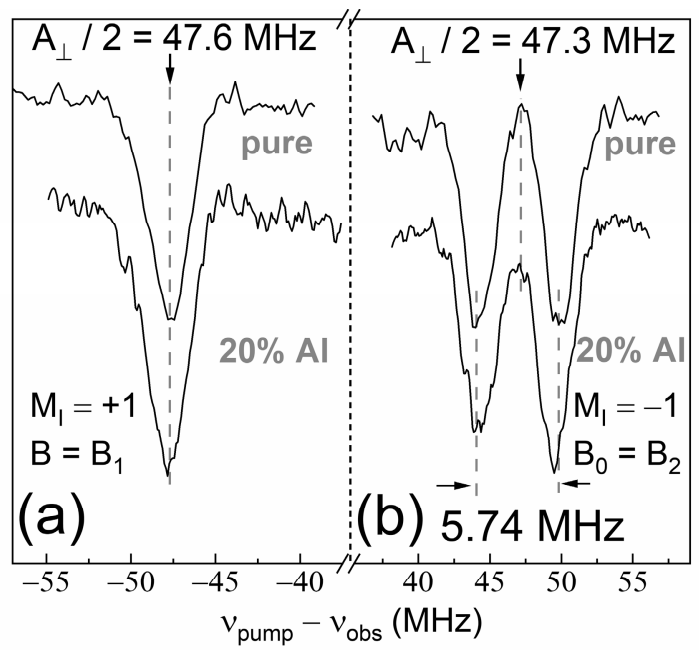

Figure 4. EDNMR spectra for the single quantum transition according to the quantum number $\mathrm{M}_{\mathrm{I}}$ : (a) $\mathrm{M}_{\mathrm{I}}=+1$ at $\mathrm{B}_{0}=\mathrm{B}_{1}$, (b) $\mathrm{M}_{\mathrm{I}}=-1$ at $\mathrm{B}_{0}=\mathrm{B}_{2}$ (see Figure $1 \mathrm{a}$ ).

One of the proofs that the splitting of the line for the single-quantum transition is actually caused by a quadrupole interaction is the presence of an angular dependence of the $P$ value:

$$
P(\theta)=P\left(3 \cos ^{2} \theta-1\right)
$$

The anisotropic EPR spectrum of the nitrate radical (Figure 1a) and a rather narrow microwave excitation band make it possible to conduct angular selected measurements of the quadrupole splitting. Indeed, in our experiments, we can clearly observe that the value of splitting significantly depends on the $\mathrm{B}_{0}$, confirming the aforementioned assumption (see Table 3). Therefore, the presence of the splitting in the EDNMR spectrum (by quadrupole interaction for a single quantum transition and by $2 v_{\text {Larmor }}$ Larmor frequency of ${ }^{14} \mathrm{~N}$ for a double quantum transition), as well as the localization of obtained signals near $A$, clearly indicate that the radiation-induced center is related to the nitrogen radical $\mathrm{NO}_{3}^{2-}$. Furthermore, this nitrogen radical can surely be used as a spin probe.

However, it should be noted that the hyperfine $A$ and quadrupole $P$ tensors are not collinear (the principal/canonical axes of the tensors do not match), which are based on the simple calculation and analysis of the angular dependencies of the $A$ and $P$ values. Earlier, a similar mutual behavior of tensors was observed in oil samples [60]. The possibility of detecting resolved EDNMR spectra is due to the good localization of the nitrogen center (in the position of phosphate, see $[37,38]$ ), which leads to the absence of local variations of $g, A$, and the electric field gradient. Such measurements make it possible to establish unequivocally the presence of a nitrogen atom in the free radical. The EDNMR method 
easily copes with cases when $A$ is much larger than $2 v_{\text {Larmor, }}$ which is almost impossible to achieve with other methods (ESEEM and ENDOR).

Table 3. Quantitative values of quadrupole interaction, depending on the external magnetic field values.

\begin{tabular}{|c|c|c|}
\hline \multirow{2}{*}{$\mathbf{B}_{0}$} & \multicolumn{2}{|c|}{$\Delta=\left|v_{\mathrm{sq} 2}-v_{\mathrm{sq} 1}\right|,(\mathrm{MHz})$} \\
\hline & $\mathrm{B}_{1}-{ }_{\Delta} \mathrm{B} ; \Delta v<0\left(\mathrm{M}_{\mathrm{I}}=+1\right)$ & $\mathrm{B}_{2}+{ }_{\Delta} \mathrm{B} ; \Delta v>0\left(\mathrm{M}_{\mathrm{I}}=-1\right)$ \\
\hline $\mathrm{B}_{0}=\mathrm{B}_{1,2}$ & 0 & 5.7 \\
\hline $\mathrm{B}_{0}=\mathrm{B}_{1,2} \pm 0.25 \mathrm{mT}$ & $\approx 0.5$ & 4.1 \\
\hline $\mathrm{B}_{0}=\mathrm{B}_{1,2} \pm 0.5 \mathrm{mT}$ & 3.83 & 2.5 \\
\hline $\mathrm{B}_{0}=\mathrm{B}_{1,2} \pm 1 \mathrm{mT}$ & 5.53 & 0 \\
\hline $\mathrm{B}_{0}=\mathrm{B}_{1,2} \pm 1.5 \mathrm{mT}$ & 5.58 & 0 \\
\hline
\end{tabular}

\subsection{Hyperfine Interaction Spectroscopy (ESEEM and ENDOR Methods)}

There are several approaches for the analysis of hyperfine interactions that cannot be registered in EPR spectra due to the small value of splitting. This section is dedicated to ESEEM (X-band) and ENDOR (X-and W-band) spectra recorded at the field positions corresponding to the maximum of echo intensity. Taking into account the wide excitation bandwidth of short microwave pulses (approx. $50 \mathrm{MHz}$ ) and significant spectra overlapping between signals of different paramagnetic centers, current X-band ENDOR measurements cannot be used to selectively address the paramagnetic centers. Nevertheless, important information can be gathered from the analysis.

The crystal lattice of $\mathrm{CP}$ samples contains ions with magnetic nuclei $\left({ }^{1} \mathrm{H}\right.$ and ${ }^{31} \mathrm{P}$ both with $I=1 / 2)$. Therefore, if the radiation-induced center is localized near these ions, we can register the corresponding signal of the electron-nuclear interaction. In the spectrum for the X-ray irradiated HA sample (Figure 5a), only signals from phosphorus nuclei $\left({ }^{31} \mathrm{P}, v_{\mathrm{z}} \approx 5.9 \mathrm{MHz}\right.$ at $\left.\mathrm{B}_{0}=340 \mathrm{mT}\right)$ are observed, although the material also contains hydrogen atoms. This result may indicate that for the HA material, the carbonate radical occupies positions near the phosphorus groups $\mathrm{PO}_{4}$. The ESEEM spectrum of the irradiated OCP sample (Figure $5 \mathrm{~b}$ ) was registered for the nitrate radical at $\mathrm{B}_{0}=341.8 \mathrm{mT}$ (see Figure 1a). The ESEEM spectrum contains a complete set of signals from all magnetic nuclei $\left({ }^{1} \mathrm{H}\right.$, $v_{\mathrm{z}} \approx 14.2 \mathrm{MHz}$ ), which indicates the position of the nitrate radical directly in the crystal lattice of the OCP sample. Consequently, in further investigations, the nitrate radical can be successfully used as a spin probe for analyzing the concentration dependences of samples doped with various impurity ions. However, the presence of a sufficiently intense signal from the hydrogen nuclei and the existence of the second harmonic of ${ }^{1} \mathrm{H}\left(2 v_{\mathrm{z}}\right)$ may indicate the localization of the nitrate radical near the hydrogen layers of OCP. The nitrogen radical in the $\mathrm{CP}$ structure can also provide the possibility of using the ENDOR method for a more detailed analysis of the nuclear environment. It is worth noting that due to the insufficient spectroscopic resolution of the method, we could not observe the additional splitting of the lines.

In contrast to other methods of measuring hyperfine interactions with neighboring magnetic ligands, the ENDOR method allows for the direct registration of NMR transitions, which significantly increases the spectral resolution. In the ENDOR spectrum of the irradiated OCP with fixed $\mathrm{B}_{0}=341 \mathrm{mT}$, signals at the Zeeman frequencies corresponding to protons $\left(v_{\mathrm{z}} \approx 14.8 \mathrm{MHz}\right)$ and phosphorous ${ }^{31} \mathrm{P}\left(v_{\mathrm{z}} \approx 5.9 \mathrm{MHz}\right)$ nuclei are observed (Figure 6). Only one broad signal for ${ }^{31} \mathrm{P}$ is detected, which can be simulated as a convolution of Gaussian and Lorentzian lines with the line widths of $1.6 \mathrm{MHz}$ and $0.4 \mathrm{MHz}$; however, in HA, a ${ }^{31} \mathrm{P}$ splitting of $0.5-1.0 \mathrm{MHz}$ can be observed $[35,36,58]$. The absence of well-structured ENDOR and ESEEM signals from phosphorous and hydrogen nuclei may be explained by the irregularity of the incorporation of several distinct (R1-R3) defects [54] into the lattice (it is either because of preferential localization in the disordered hydrated layer or due to a large variety of incorporation sites in the apatite layer). Most probably, in 
line with the discussion on the EPR parameters given above, this means that the radical(s) are not located in the majority of apatite crystallites (A- or B-type substitution) but in the hydrated layers [61].
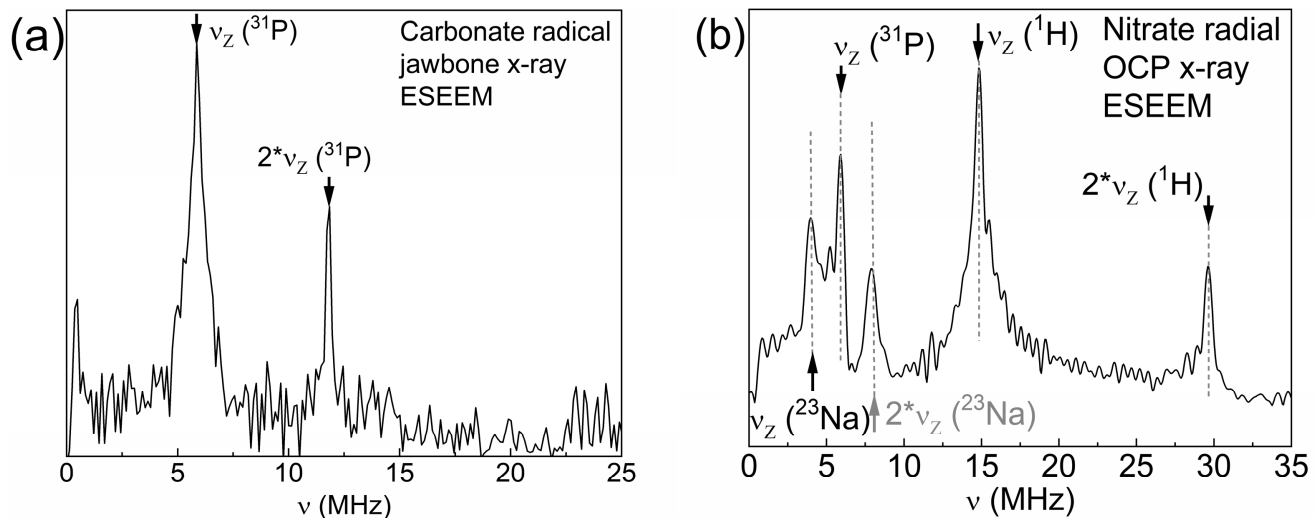

Figure 5. ESEEM spectra of irradiated jawbone containing HA (a) and OCP (b) samples registered in a perpendicular orientation $\left(\mathrm{B}_{0}\right)$ of carbonate and nitrate radicals, respectively (see Figure $1 \mathrm{a}$ ).

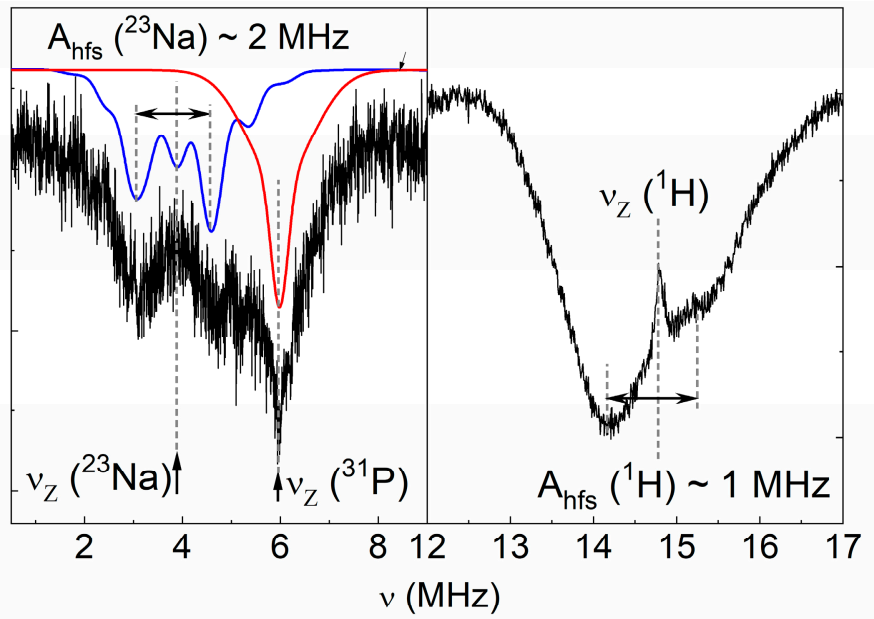

Figure 6. $X$-band ENDOR spectra detected at $\mathrm{B}_{0}$ (see Figure $1 \mathrm{a}$ ) and $\mathrm{T}=100 \mathrm{~K}$ of the OCP sample after X-ray irradiation.

Other features of the ESEEM and ENDOR spectra can be ascribed to the interaction with ${ }^{23} \mathrm{Na}$ nuclei $\left(v_{\mathrm{z}} \approx 3.9 \mathrm{MHz}\right.$ at $\mathrm{B}_{0}=340 \mathrm{mT}, I=3 / 2$ and, therefore, quadrupolar). The presence of a signal from ${ }^{23} \mathrm{Na}$ nuclei is probably due to the incorporation of sodium into the OCP lattice during the synthesis stage. Similar results without deep analysis have been reported in some papers devoted to apatite investigations (see [61], for example). Frequently, the quadrupolar interaction makes the ${ }^{23} \mathrm{Na}$ spectra too complicated for analysis. Using the EasySpin procedure salt for ENDOR spectra simulations and assuming an isotropic interaction, we were able to estimate $A_{23 \mathrm{Na}}=1.5 \mathrm{MHz}$ and $\mathrm{e}^{2} \mathrm{Qq} / \mathrm{h}=3.3 \mathrm{MHz}$ (Figure 6).

\section{Conclusions}

In this paper, we studied calcium phosphate materials using diverse magnetic resonance approaches. The powders under study were exposed to X-ray/gamma radiation to create paramagnetic centers (free radicals). The EPR method makes it possible to distinguish the types of radiation-induced paramagnetic centers in different samples through the values of the Spin-Hamiltonian parameters and dynamic (relaxation) characteristics. Methods targeted to the analysis of weak hyperfine interactions (EDNMR, ESEEM, and ENDOR) demonstrated their advantage in the characterization of synthetic calcium phos- 
phate powder samples. The EDNMR method allows for the determination of the value of the quadrupole interaction for the nitrogen radical, which is a sensitive parameter of the local gradient of the electric (crystal) field. It is possible to identify the various nuclear environments and estimate the position of the radiation-induced centers by ESEEM spectroscopy, while ENDOR provides extensive information about local structural changes caused by the introduction of even non-paramagnetic ions.

Author Contributions: The research work was performed and completed through the contributions of all authors. S.B.O., M.R.G., and V.S.K. designed and administered the experiments. F.F.M., B.V.Y., A.A., and G.V.M. conducted all EPR, ESEEM, ENDOR, and EDNMR experiments. P.O.G., F.F.M., and M.R.G. wrote the main part of the manuscript. M.A.G., N.V.P., and A.Y.F. performed the sample synthesis and characterization. All authors analyzed and discussed the data. All authors have read and agreed to the published version of the manuscript.

Funding: Authors would like to thank the Russian Foundation for Basic Research, project no. 1829-11086. Institute of Solid State Physics, University of Latvia as the Center of Excellence received funding from the European Union's Horizon 2020 Framework Programme H2020-WIDESPREAD-012016-2017- TeamingPhase2 under grant agreement No. 739508, project CAMART ${ }^{2}$.

Informed Consent Statement: Not applicable.

Data Availability Statement: Data can be available upon request from the authors.

Conflicts of Interest: The authors declare no conflict of interest.

\section{References}

1. Habibovic, P.; Barralet, J.E. Bioinorganics and biomaterials: Bone repair. Acta Biomater. 2011, 7, 3013-3026. [CrossRef] [PubMed]

2. Habraken, W.; Habibovic, P.; Epple, M.; Bohner, M. Calcium phosphates in biomedical applications: Materials for the future? Mater. Today 2016, 19, 69-87. [CrossRef]

3. Epple, M.; Ganesan, K.; Heumann, R.; Klesing, J.; Kovtun, A.; Neumann, S.; Sokolova, V.J.J.C. Application of calcium phosphate nanoparticles in biomedicine. J. Mater. Chem. 2010, 20, 18-23. [CrossRef]

4. Insley, G.; Suzuki, O. Octacalcium Phosphate Biomaterials: Understanding of Bioactive Properties and Application, 1st ed.; Woodhead Publishing: Cambridge, UK, 2019.

5. Bazin, D.; Daudon, M. Physicochemistry in medicine: Some selected examples. J. Spectr. Imaging 2019, 8, a16. [CrossRef]

6. Bohner, M. Resorbable biomaterials as bone graft substitutes. Mater. Today 2010, 13, 24-30. [CrossRef]

7. Goldberg, M.A.; Smirnov, V.V.; Teterina, A.Y.; Barinov, S.M.; Komlev, V.S. Trends in development of bioresorbable calcium phosphate ceramic materials for bone tissue engineering. Polym. Sci. Ser. D 2018, 11, 419-422. [CrossRef]

8. de Groot, K. Ceramics of Calcium Phosphates: Preparation and Properties. In Bioceramics Calcium Phosphate, 1st ed.; CRC Press: Boca Raton, FL, USA, 2018.

9. LeGeros, R.Z. Calcium phosphate-based osteoinductive materials. Chem. Rev. 2008, 108, 4742-4753. [CrossRef]

10. Silvestri, A.; Boffito, M.; Sartori, S.; Ciardelli, G. Biomimetic materials and scaffolds for myocardial tissue regeneration. Macromol. Biosci. 2013, 13, 984-1019. [CrossRef] [PubMed]

11. Ridi, F.; Meazzini, I.; Castroflorio, B.; Bonini, M.; Berti, D.; Baglioni, P. Functional calcium phosphate composites in nanomedicine. Adv. Colloid Interface Sci. 2017, 244, 281-295. [CrossRef] [PubMed]

12. Victor, S.P.; Paul, W.; Sharma, C.P. Calcium phosphate nanoplatforms for drug delivery and theranostic applications. In Drug Delivery Nanosystems for Biomedical Applications, 1st ed.; Elsevier: Amsterdam, The Netherlands, 2018.

13. Haider, A.; Haider, S.; Han, S.S.; Kang, I.K. Recent advances in the synthesis, functionalization and biomedical applications of hydroxyapatite: A review. RSC Adv. 2017, 7, 7442-7458. [CrossRef]

14. Epple, M. Review of potential health risks associated with nanoscopic calcium phosphate. Acta Biomater. 2018, 77, 1-14. [CrossRef] [PubMed]

15. Lu, J.; Yu, H.; Chen, C. Biological properties of calcium phosphate biomaterials for bone repair: A review. RSC Adv. 2018, 8, 2015-2033. [CrossRef]

16. Zhou, C.; Hong, Y.; Zhang, X. Applications of nanostructured calcium phosphate in tissue engineering. Biomater. Sci. 2013, 1, 1012-1028. [CrossRef] [PubMed]

17. Šupová, M. Substituted hydroxyapatites for biomedical applications: A review. Ceram. Int. 2015, 41, 9203-9231. [CrossRef]

18. Hui, J.; Wang, X. Hydroxyapatite nanocrystals: Colloidal chemistry, assembly and their biological applications. Inorg. Chem. Front. 2014, 1, 215-225. [CrossRef]

19. Idini, A.; Frau, F.; Gutierrez, L.; Dore, E.; Nocella, G.; Ghiglieri, G. Application of octacalcium phosphate with an innovative household-scale defluoridator prototype and behavioral determinants of its adoption in rural communities of the East African Rift Valley. Integr. Environ. Assess. Manag. 2020, 16, 856-870. [CrossRef] 
20. Sundaram, C.S.; Viswanathan, N.; Meenakshi, S. Defluoridation chemistry of synthetic hydroxyapatite at nano scale: Equilibrium and kinetic studies. J. Hazard. Mater. 2008, 155, 206-215. [CrossRef] [PubMed]

21. Sebti, S.; Tahir, R.; Nazih, R.; Saber, A.; Boulaajaj, S. Hydroxyapatite as a new solid support for the Knoevenagel reaction in heterogeneous media without solvent. Appl. Catal. A 2002, 228, 155-159. [CrossRef]

22. Saha, B.; Yadav, S.K.; Sengupta, S. Synthesis of nano-Hap prepared through green route and its application in oxidative desulfurisation. Fuel 2018, 222, 743-752. [CrossRef]

23. Riad, M.; Mikhail, S. Oxidative desulfurization of light gas oil using zinc catalysts prepared via different techniques. Catal. Sci. Technol. 2012, 2, 1437-1446. [CrossRef]

24. Pillai, U.R.; Sahle-Demessie, E. Epoxidation of olefins and $\alpha, \beta$-unsaturated ketones over sonochemically prepared hydroxyapatites using hydrogen peroxide. Appl. Catal. A 2004, 261, 69-76. [CrossRef]

25. Carmona, F.J.; Dal Sasso, G.; Bertolotti, F.; Ramírez-Rodríguez, G.B.; Delgado-López, J.M.; Pedersen, J.S.; Masciocchi, N.; Guagliardi, A. The role of nanoparticle structure and morphology in the dissolution kinetics and nutrient release of nitrate-doped calcium phosphate nanofertilizers. Sci. Rep. 2020, 10, 12396. [CrossRef]

26. Wijesinghe, W.P.S.L.; Mantilaka, M.M.M.G.P.G.; Peiris, T.N.; Rajapakse, R.M.G.; Wijayantha, K.U.; Pitawala, H.M.T.G.A.; Premachandra, T.N.; Herath, H.M.T.U.; Rajapakse, R.P.V.J. Preparation and characterization of mesoporous hydroxyapatite with non-cytotoxicity and heavy metal adsorption capacity. New J. Chem. 2018, 42, 10271-10278. [CrossRef]

27. Islam, M.; Mishra, P.C.; Patel, R. Physicochemical characterization of hydroxyapatite and its application towards removal of nitrate from water. J. Environ. Manag. 2010, 91, 1883-1891. [CrossRef]

28. Raza, M.; Zahid, S.; Asif, A. Analytical tools for substituted hydroxyapatite. In Handbook of Ionic Substituted Hydroxyapatites; Elsevier: Amsterdam, The Netherlands, 2020; pp. 21-51.

29. Abdul'Yanov, V.A.; Galiullina, L.; Galyavich, A.; Izotov, V.G.; Mamin, G.; Orlinskii, S.; Rodionov, A.A.; Salakhov, M.K.; Silkin, N.I.; Sitdikova, L.M.; et al. Stationary and high-frequency pulsed electron paramagnetic resonance of a calcified atherosclerotic plaque. JETP Lett. 2008, 88, 69-73. [CrossRef]

30. Gafurov, M.; Chelyshev, Y.; Ignatyev, I.; Zanochkin, A.; Mamin, G.; Iskhakova, K.; Kiiamov, A.; Murzakhanov, F.; Orlinskii, S.

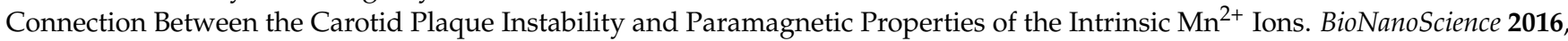
6, 558-560. [CrossRef]

31. Gabbasov, B.; Gafurov, M.; Starshova, A.; Shurtakova, D.; Murzakhanov, F.; Mamin, G.; Orlinskii, S. Conventional, pulsed and high-field electron paramagnetic resonance for studying metal impurities in calcium phosphates of biogenic and synthetic origins. J. Magn. Magn. Mater. 2019, 470, 109-117. [CrossRef]

32. Murzakhanov, F.; Gabbasov, B.; Iskhakova, K.; Voloshin, A.; Mamin, G.; Putlyaev, V.; Klimashina, E.; Fadeeva, I.; Fomin, A.; Barinov, S.; et al. Conventional electron paramagnetic resonance for studying synthetic calcium phosphates with metal impurities $\left(\mathrm{Mn}^{2+}, \mathrm{Cu}^{2+}, \mathrm{Fe}^{3+}\right)$. Magn. Reson. Solids 2017, 19, 17207-17210.

33. Fadeeva, I.V.; Gafurov, M.R.; Kiiaeva, I.A.; Orlinskii, S.B.; Kuznetsova, L.M.; Filippov, Y.Y.; Fomin, A.S.; Davydova, G.A.; Selezneva, I.I.; Barinov, S.M. Tricalcium phosphate ceramics doped with silver, copper, zinc, and iron (III) ions in concentrations of less than $0.5 \mathrm{wt}$ \% for bone tissue regeneration. BioNanoScience 2017, 7, 434-438. [CrossRef]

34. Chelyshev, Y.; Gafurov, M.; Ignatyev, I.; Zanochkin, A.; Mamin, G.; Sorokin, B.; Sorokina, A.; Lyapkalo, N.; Gizatullina, N.; Mukhamedshina, Y.; et al. Paramagnetic Manganese in the Atherosclerotic Plaque of Carotid Arteries. BioMed Res. Int. 2016, 2016, 3706280. [CrossRef] [PubMed]

35. Goldberg, M.; Gafurov, M.; Makshakova, O.; Smirnov, V.; Komlev, V.; Barinov, S.; Kudryavtsev, E.; Sergeeva, N.; Achmedova, S.; Mamin, G.; et al. Influence of $\mathrm{Al}$ on the structure and in vitro behavior of hydroxyapatite nanopowders. J. Phys. Chem. B 2019, 123, 9143-9154. [CrossRef] [PubMed]

36. Gafurov, M.; Biktagirov, T.; Mamin, G.; Orlinskii, S. A DFT, X-and W-band EPR and ENDOR study of nitrogen-centered species in (nano) hydroxyapatite. Appl. Magn. Reson. 2014, 45, 1189-1203. [CrossRef]

37. Gafurov, M.; Biktagirov, T.; Yavkin, B.; Mamin, G.; Filippov, Y.; Klimashina, E.; Putlayev, V.; Orlinskii, S. Nitrogen-containing species in the structure of the synthesized nano-hydroxyapatite. JETP Lett. 2014, 99, 196-203. [CrossRef]

38. Biktagirov, T.; Gafurov, M.; Mamin, G.; Klimashina, E.; Putlayev, V.; Orlinskii, S. Combination of EPR measurements and DFT calculations to study nitrate impurities in the carbonated nanohydroxyapatite. J. Phys. Chem. B 2014, 118, 1519-1526. [CrossRef]

39. Yavkin, B.V.; Mamin, G.V.; Orlinskii, S.B.; Gafurov, M.R.; Salakhov, M.K.; Biktagirov, T.B.; Klimashina, E.S.; Putlayev, V.I.; Tretyakov, Y.D.; Silkin, N.I. $\mathrm{Pb}^{3+}$ radiation defects in $\mathrm{Ca}_{9} \mathrm{~Pb}\left(\mathrm{PO}_{4}\right)_{6}(\mathrm{OH})_{2}$ hydroxyapatite nanoparticles studied by high-field (W-band) EPR and ENDOR. Phys. Chem. Chem. Phys. 2012, 14, 2246-2249. [CrossRef]

40. Vorona, I.P.; Nosenko, V.V.; Baran, N.P.; Ishchenko, S.S.; Lemishko, S.V.; Zatovsky, I.V.; Strutynska, N.Y. EPR study of radiationinduced defects in carbonate-containing hydroxyapatite annealed at high temperature. Radiat. Meas. 2016, 87, 49-55. [CrossRef]

41. Fattibene, P.; Callens, F. EPR dosimetry with tooth enamel: A review. Appl. Radiat. Isot. 2010, 68, 2033-2116. [CrossRef] [PubMed]

42. Goldberg, M.A.; Akopyan, A.V.; Gafurov, M.R.; Makshakova, O.N.; Donskaya, N.O.; Fomin, A.S.; Polikarpova, P.P.; Anisimov, A.V.; Murzakhanov, F.F.; Leonov, A.V.; et al. Iron-Doped Mesoporous Powders of Hydroxyapatite as Molybdenum-Impregnated Catalysts for Deep Oxidative Desulfurization of Model Fuel: Synthesis and Experimental and Theoretical Studies. J. Phys. Chem. C 2021, 125, 11604-11619. [CrossRef] 
43. Goldberg, M.A.; Gafurov, M.R.; Murzakhanov, F.F.; Fomin, A.S.; Antonova, O.S.; Khairutdinova, D.R.; Pyataev, A.V.; Makshakova, O.N.; Konovalov, A.A.; Leonov, A.V.; et al. Mesoporous Iron(III)-Doped Hydroxyapatite Nanopowders Obtained via Iron Oxalate. Nanomaterials 2021, 11, 811. [CrossRef] [PubMed]

44. Gustafsson, H.; Hallbeck, M.; Lindgren, M.; Kolbun, N.; Jonson, M.; Engström, M.; de Muinck, E.; Zachrisson, H. Visualization of oxidative stress in ex vivo biopsies using electron paramagnetic resonance imaging. Magn. Reson. Med. 2015, 73, 1682-1691. [CrossRef] [PubMed]

45. Gilinskaya, L.G. Organic radicals in natural apatites according to EPR data: Potential genetic and paleoclimatic indicators. J. Struct. Chem. 2010, 51, 471-481. [CrossRef]

46. Fisher, B.V.; Morgan, R.E.; Phillips, G.O.; Wardale, H.W. Radiation damage in calcium phosphates and collagen: An interpretation of ESR spectra. Radiat. Res. 1971, 46, 229-235. [CrossRef]

47. Cevc, P.; Schara, M.; Ravnik, Č. Electron paramagnetic resonance study of irradiated tooth enamel. In Radiation Research; Radiation Research Society: Lawrence, UK, 1972; Volume 51, pp. 581-589. [CrossRef]

48. Vanhaelewyn, G.C.A.M.; Sadlo, J.; Matthys, P.F.A.E.; Callens, F.J. Comparative X-and Q-band EPR study of radiation-induced radicals in tooth enamel. Radiat. Res. 2002, 158, 615-625. [CrossRef]

49. Vanhaelewyn, G.C.A.M.; Morent, R.A.; Callens, F.J.; Matthys, P.F.A.E. X-and Q-band electron paramagnetic resonance of $\mathrm{CO}_{2}-$ in hydroxyapatite single crystals. Radiat. Res. 2000, 154, 467-472. [CrossRef]

50. Wencka, M.; Hoffmann, S.K.; Hercman, H. EPR dating of hydroxyapatite from fossil bones. Transient Effects after gamma and UV irradiation. Acta Phys. Pol. A 2005, 108, 331. [CrossRef]

51. Erceg, I.; Maltar-Strmečki, N.; Jurašin, D.D.; Strasser, V.; Ćurlin, M.; Lyons, D.M.; Radatović, B.; Mlinarić, N.M.; Kralj, D.; Sikirić, M.D. Comparison of the Effect of the Amino Acids on Spontaneous Formation and Transformation of Calcium Phosphates. Crystals 2021, 11, 792. [CrossRef]

52. Ebrahimi, M.; Botelho, M.; Lu, W.; Monmaturapoj, N. Synthesis and characterization of biomimetic bioceramic nanoparticles with optimized physicochemical properties for bone tissue engineering. J. Biomed. Mater. Res. Part A 2019, 107, 1654-1666. [CrossRef]

53. Gol'dberg, M.A.; Smirnov, V.V.; Ievlev, V.M.; Barinov, S.M.; Kutsev, S.V.; Shibaeva, T.V.; Shvorneva, L.I. Influence of ripening time on the properties of hydroxyapatite-calcium carbonate powders. Inorg. Mater. 2012, 48, 181-186. [CrossRef]

54. Shurtakova, D.V.; Yavkin, B.V.; Mamin, G.V.; Orlinskii, S.B.; Sirotinkin, V.P.; Fedotov, A.Y.; Shinkarev, A.; Antuzevics, A.; Smirnov, I.V.; Tovtin, V.I.; et al. X-Ray Diffraction and Multifrequency EPR Study of Radiation-Induced Room Temperature Stable Radicals in Octacalcium Phosphate. Radiat. Res. 2021, 195, 200-210. [CrossRef]

55. Shurtakova, D.; Yavkin, B.; Gafurov, M.; Mamin, G.; Orlinskii, S.; Kuznetsova, L.; Bakhteev, S.; Ignatyev, I.; Smirnov, I.; Fedotov, A.; et al. Study of radiation-induced stable radicals in synthetic octacalcium phosphate by pulsed EPR. Magn. Reson. Solids 2019, 21, 19105. [CrossRef]

56. Baran, N.P.; Vorona, I.P.; Ishchenko, S.S.; Nosenko, V.V.; Zatovskii, I.V.; Gorodilova, N.A.; Povarchuk, V.Y. $\mathrm{NO}_{3}{ }^{2-}$ and $\mathrm{CO}_{2}{ }^{-}$ centers in synthetic hydroxyapatite: Features of the formation under $\gamma$-and UV-irradiations. Phys. Solid State 2011, 53, 1891-1894. [CrossRef]

57. Nosenko, V.V.; Vorona, I.P.; Ishchenko, S.S.; Baran, N.P.; Zatovsky, I.V.; Gorodilova, N.A.; Povarchuk, V.Y. Effect of pre-annealing on $\mathrm{NO}_{3}{ }^{2-}$ centers in synthetic hydroxyapatite. Radiat. Meas. 2012, 47, 970-973. [CrossRef]

58. Goldfarb, D. ELDOR-Detected NMR. eMagRes 2007, 6, 101-114. [CrossRef]

59. Wili, N.; Richert, S.; Limburg, B.; Clarke, S.J.; Anderson, H.L.; Timmel, C.R.; Jeschke, G. ELDOR-detected NMR beyond hyperfine couplings: A case study with Cu (ii)-porphyrin dimers. Phys. Chem. Chem. Phys. 2019, 21, 11676-11688. [CrossRef] [PubMed]

60. Gracheva, I.N.; Gafurov, M.R.; Mamin, G.V.; Biktagirov, T.B.; Rodionov, A.A.; Galukhin, A.V.; Orlinskii, S.B. ENDOR study of nitrogen hyperfine and quadrupole tensors in vanadyl porphyrins of heavy crude oil. Magn. Reson. Solids 2016, $18,16102$.

61. Moens, P.D.W.; Callens, F.J.; Boesman, E.R.; Verbeeck, R.M.H. ${ }^{1} \mathrm{H}$ and ${ }^{31} \mathrm{P}$ ENDOR of the isotropic $\mathrm{CO}_{2}{ }^{-}$signal at $\mathrm{g}=2.0007$ in the EPR spectra of precipitated carbonated apatites. Appl. Magn. Reson. 1995, 9, 103-113. [CrossRef] 